\title{
New national recommendations for the treatment of pediatric differentiated thyroid carcinoma in the Netherlands
}

\author{
C A Lebbink 101,2, B L Dekker³, G Bocca4, A J A T Braat2,5, J P M Derikx6, M P Dierselhuis², B de Keizer2,5, S Kruijff7, \\ A B G Kwast ${ }^{8}$, F H van Nederveen ${ }^{\text {, }}$ E J M Nieveen van Dijkum ${ }^{10}$, R A J Nievelstein ${ }^{2,5}$, R P Peeters ${ }^{11}$, \\ C E J Terwisscha van Scheltinga ${ }^{2}$, W J E Tissing ${ }^{2,12}$, K van der Tuin ${ }^{11}{ }^{13}$, M R Vriens ${ }^{14}$, J Zsiros ${ }^{2}$, \\ A S P van Trotsenburg ${ }^{15}$, T $_{\text {P Links }}^{3}$ and $\mathbf{H}$ M van Santen $\mathbb{D}^{1,2}$
}

1Department of Pediatric Endocrinology, Wilhelmina Children's Hospital (WKZ)/University Medical Center Utrecht (UMCU), Utrecht, The Netherlands, 2Princess Máxima Center for Pediatric Oncology, Utrecht, The Netherlands, ${ }^{3}$ Department of Endocrinology, Internal Medicine, University of Groningen, University Medical Center Groningen (UMCG), Groningen, The Netherlands, ${ }^{4}$ Department of Pediatric Endocrinology, Beatrix Children's Hospital, University of Groningen, University Medical Center Groningen (UMCG), Groningen, The Netherlands, ${ }^{5}$ Department of Radiology and Nuclear Medicine, Imaging Division, University Medical Center Utrecht (UMCU), Utrecht, The Netherlands, ${ }^{6}$ Department of Pediatric Surgery, Pediatric Surgical Center of Amsterdam, Emma Children's Hospital, Amsterdam University Medical Center, Amsterdam, The Netherlands, ${ }^{7}$ Division of Surgical Oncology, Department of Surgery, University of Groningen, University Medical Center Groningen (UMCG), Groningen, The Netherlands, ${ }^{8}$ Comprehensive Cancer Center, The Netherlands, ${ }^{9}$ Laboratorium voor Pathologie (PAL), Dordrecht, The Netherlands, ${ }^{10}$ Department of Surgery, Cancer Center Amsterdam, Amsterdam University Medical Center, University of Amsterdam, Amsterdam, The Netherlands, ${ }^{11}$ Department of Endocrinology, Erasmus Medical Center (EMC), Rotterdam, The Netherlands, ${ }^{12}$ Department of Pediatric Oncology, Beatrix Children's Hospital, University of Groningen, University Medical Center Groningen (UMCG), Groningen, The Netherlands, ${ }^{13}$ Department of Clinical Genetics, Leiden University Medical Center (LUMC), Leiden, The Netherlands, ${ }^{14}$ Department of Surgery, Wilhelmina Children's Hospital (WKZ)/University Medical Center Utrecht (UMCU), Utrecht, The Netherlands, and ${ }^{15}$ Department of Pediatric Endocrinology, Emma Children's Hospital, Amsterdam University Medical Center, University of Amsterdam, Amsterdam, The Netherlands

Correspondence should be addressed to $\mathrm{H}$ M van Santen Email h.m.vansanten@umcutrecht.nl

\begin{abstract}
Background: Currently, there are no European recommendations for the management of pediatric thyroid cancer. Other current international guidelines are not completely concordant. In addition, medical regulations differ between, for instance, the US and Europe. We aimed to develop new, easily accessible national recommendations for differentiated thyroid carcinoma (DTC) patients $<18$ years of age in the Netherlands as a first step toward a harmonized European Recommendation.
\end{abstract}

Methods: A multidisciplinary working group was formed including pediatric and adult endocrinologists, a pediatric radiologist, a pathologist, endocrine surgeons, pediatric surgeons, pediatric oncologists, nuclear medicine physicians, a clinical geneticist and a patient representative. A systematic literature search was conducted for all existing guidelines and review articles for pediatric DTC from 2000 until February 2019. The Appraisal of Guidelines, Research and Evaluation (AGREE) instrument was used for assessing quality of the articles. All were compared to determine dis- and concordances. The American Thyroid Association (ATA) pediatric guideline 2015 was used as framework to develop specific Dutch recommendations. Discussion points based upon expert opinion and current treatment management of DTC in children in the Netherlands were identified and elaborated.

Results: Based on the most recent evidence combined with expert opinion, a 2020 Dutch recommendation for pediatric DTC was written and published as an online interactive decision tree (www.oncoguide.nl).

Conclusion: Pediatric DTC requires a multidisciplinary approach. The 2020 Dutch Pediatric DTC Recommendation can be used as a starting point for the development of a collaborative European recommendation for treatment of pediatric DTC.

(C) 2020 European Society of Endocrinology Printed in Great Britain
European Journal of Endocrinology

(2020) 183, P11-P18 


\section{Background}

Pediatric thyroid cancer is a rare disease; however, its worldwide incidence rate is increasing $(1,2)$. Differentiated thyroid carcinoma (DTC) is the most common form of this disease and comprises 3\% of all pediatric tumors, with 0.2 to 3 cases per million children per year $(3,4)$. In the Netherlands, in a 43-year period, 170 children with DTC were identified (5). In 2015, the American Thyroid Association developed a special recommendation for pediatric nodules and thyroid cancer (6), but in Europe, such a recommendation is not yet available. Because regulations for medical care differ between the US and Europe, next to possible cultural differences, specific European and national recommendations are required.

Compared to adult DTC, pediatric DTC presents with more advanced disease, expressed as more frequent lymph node involvement at diagnosis, distant metastases and multifocal disease. Despite this more aggressive presentation, pediatric DTC has an excellent prognosis in terms of survival rates (1). Also, differences exist between adult and pediatric DTC with regard to histology and molecular characteristics $(7,8)$. For children, treatmentrelated late effects may be more important than for adults, because of the longer life span. The rareness of the disease, in combination with the aforementioned clinical, histological and molecular differences, differences in intercontinental medical regulations, and the importance of minimizing late effects, emphasizes the need for a national and European pediatric DTC recommendation.

As in many other countries, also in the Netherlands centralization of care is seen as the best way forward to improve care for rare diseases. For children with thyroid cancer, there was need for harmonization of diagnostic work-up, management strategy and follow-up targets. To achieve optimal care for the Dutch population, a national multidisciplinary working group was formed aiming at the development of harmonized Dutch recommendations for DTC patients < 18 years of age. Secondly, this work may be used as first step to develop a harmonized European recommendation.

\section{Methods}

To develop Dutch recommendations, a committee of experts was composed, including pediatric and adult endocrinologists, a pediatric radiologist, a pathologist, endocrine surgeons, pediatric surgeons, nuclear medicine physicians, an epidemiologist, a clinical geneticist, a pediatric oncologist and a patient representative.
The working group agreed to write the new Dutch recommendation using a guideline adaptation process instead of producing a de novo Dutch DTC recommendation. Given the existence of several pediatric DTC guidelines and reviews, this was considered to be the most efficient way.

Next to the committee of experts, three co-chairs and two PhD students were assigned to the project. For efficiency, three working groups were formed: (1) diagnostics and follow-up, (2) surgery and (3) nuclear medical treatment and imaging. All experts represented their own discipline in the working group.

\section{Guideline search}

A systematic literature search was conducted in Pubmed to find all existing recommendations and review articles. The complete search terms can be found in Appendix A (see section on supplementary materials given at the end of this article). In total, 813 studies were found and abstracts were screened using the following inclusion criteria: (1) studies describing the management of DTC in patients <18 years, (2) studies written in English or Dutch and (3) studies published after 2000 or an updated elder original article. In total, six guidelines or review articles on treatment of pediatric DTC were retrieved for further evaluation of their quality with the Appraisal of Guidelines, Research and Evaluation (AGREE) instrument $(6,9,10,11,12,13,14)$. The six included guidelines were scored in six domains of a seven-point scale (1=strongly disagree, 7 =strongly agree; Appendix A). According to this system, the recommendation of the American Thyroid Association (ATA) for pediatric thyroid nodules and DTC was reviewed as the highest quality guideline (6). Therefore, it was agreed to use this recommendation as the cornerstone to develop recommendations for the Dutch population.

The next step was identifying discussion points in the current ATA recommendations based on the current Dutch diagnostics, treatment and follow-up policy, expert opinion and new available evidence. To answer additional research questions resulting from this process, new systematic literature searches were performed in Pubmed (Appendix A).

\section{Results}

Based on the most recent evidence in combination with expert opinion, recommendations for management 
of pediatric DTC were developed. The new Dutch recommendations can be found in the Appendix and online (www.oncoguide.nl).

\section{Recommendations}

\section{Organization of patient care}

A child with suspicion of DTC, proven DTC or (suspicion of) MEN syndrome should be referred to a hospital with an experienced multidisciplinary thyroid team (defined as level four hospital; Appendix 1, Fig. 1), including at least a pediatric and adult endocrinologist, pediatric radiologist, endocrine surgeon (a 'high volume' thyroid surgeon), pediatric surgeon experienced in thyroid surgery, pathologist, nuclear medicine physician, clinical geneticist, pediatric psychologist and a pediatric oncologist.

\section{Diagnostics}

- Fine needle aspiration cytology (FNAC) is recommended for thyroid nodules $\geq 1 \mathrm{~cm}$ or increased suspicion of DTC because of the presence of suspicious ultrasound (US) characteristics (taller than wide, microcalcifications, irregular margins, hypoechogenicity, solid pattern, intranodular vascularity, shape and halo sign absence) or clinical context (15).

- Next to molecular gene analysis on cytological material of suspicious nodules (Bethesda 5) for the presence of BRAF mutations, it may be considered to analyze the presence of other oncogenic drivers and gene-fusions such as RET/PTC and NTRK-fusions due to the fact that these may also be associated with presence of PTC. These results should always be discussed in the (national) multidisciplinary team to stratify care.

- The recommended surgical intervention in case of Bethesda 1-4 depends on the likelihood of the thyroid nodule(s) being malignant (e.g. size $\geq 4 \mathrm{~cm}$, trachea compression, and sonographic features-like microcalcifications, irregular margins, hypoechogenicity, solid pattern, intranodular vascularity, shape and halo sign absence) (15), and patient preference (e.g. cosmetic reasons).

- The absence of BRAF in FNAC specimen does not rule out presence of PTC, as BRAF is only identified in $40 \%$ of pediatric PTC. For this reason, diagnostic hemithyroidectomy is advised.

- In case of FNAC result with Bethesda 5 in a nodule positive for a BRAF mutation or in Bethesda 6, total thyroidectomy is advised after preoperative evaluation.

\section{Preoperative management}

- A comprehensive US of all neck regions by an experienced pediatric radiologist should be performed.

- In case of substantial cervical lymphadenopathy, a low dose CT thorax without contrast should be considered.

- In case of large or fixed thyroid masses, vocal cord paralysis, bulky metastatic lymphadenopathy or tumor invasion in the esophagus or trachea determined by physical examination or US, preoperative MRI should be considered.

- FNAC is recommended for suspicious lateral lymph nodes (size, aspect or US characteristics), but refraining from cytological confirmation is possible in case of an evident (pathological) lateral lymph node.

- Prophylactic vitamin D (and possibly calcium) treatment is recommended for reducing the risk of (possible) post-thyroidectomy hypocalcemia.

\section{Operative management}

- Total thyroidectomy is strongly recommended for all children with DTC.

- For some selected pediatric patients, there could be an indication for lobectomy or hemithyroidectomy. Such children (all children with microcarcinoma (tumor $<1$ $\mathrm{cm}$, limited to the thyroid gland and no signs of cervical lymphadenopathy)) should be discussed in the national multidisciplinary (tumor board) consultation to decide whether one could refrain from total thyroidectomy and choose for lobectomy or hemithyroidectomy.

- Routine prophylactic central or lateral neck dissection is not recommended.

- Lateral lymph node dissection should be performed in all children with preoperative proven lymph node metastases or in case of evident (pathological) lateral lymph node(s).

\section{Postoperative therapy}

- Postoperative restaging with a ${ }^{123} \mathrm{I}^{-}$whole-body scan (WBS) is not recommended.

- It is recommended that all pediatric DTC patients are treated postoperatively with ${ }^{131} \mathrm{I}^{-}$. An exception can be made for children with microcarcinoma (tumor $<1 \mathrm{~cm}$, limited to the thyroid gland). This individual treatment policy should be discussed in the national multidisciplinary meeting.

- Before the administration of ${ }^{131} \mathrm{I}^{-}$therapy, semen preservation should be discussed with all (post) 
pubertal boys (Tanner stage III and higher and able to produce semen).

- The ${ }^{131} \mathrm{I}^{-}$activity depends on extent of surgery, tumor size, presence of metastases, body weight and pubertal stage (Table 1).

- After ${ }^{131} \mathrm{I}^{-}$treatment, a WBS 4 to 7 days post-treatment is advised.

- All patients should be discussed in the national multidisciplinary (tumor board) consultation.

\section{Follow-up}

- Stratification of pediatric patients based on the risk of persistent cervical disease and/or distant metastases is recommended.

- Neck ultrasound should be performed in the follow-up of all patients, independent of the ATA pediatric risk level.

- The desired thyroid-stimulating hormone (TSH) suppression level should be determined by current disease status and ATA risk levels.

- Serum thyroglobulin (Tg) concentrations should be measured 3, 6, (ON), and 12 months (OFF) after ${ }^{131} \mathrm{I}^{-}$ therapy; thereafter, timing and frequency should be guided by the ATA pediatric risk level.

- In patients with visible thyroid tissue or suspect lymph nodes on neck US during follow-up, surgical consultation, FNAC and additional nuclear imaging are advised.

- In case of detectable Tg and negative neck US, additional imaging with FDG-PET is recommended. In these cases, ${ }^{131} \mathrm{I}^{-}$treatment without preceding nuclear imaging may be considered dependent on Tg concentration, previous lymph node dissections or presence of distant metastases.

- It is recommended to have an interval of at least 12 months between the first and a subsequent ${ }^{131} \mathrm{I}^{-}$treatment.

\section{Distant metastases}

- All patients with distant metastases should be discussed in the national multidisciplinary (tumor board) with regards to follow-up and possible additional therapy.

\section{Discussion}

Harmonization of care for children with rare diseases is necessary to improve the outcome of disease. Differences between Dutch pediatric DTC patients and American pediatric DTC patients may exist (16). For this reason specific Dutch recommendations were aimed for. These new Dutch recommendations for the treatment of pediatric DTC have been formulated based on current international recommendations (the ATA pediatric DTC guideline) and the most recent available evidence in combination with expert opinion. Next to harmonization of care, organization of care was also addressed with the intention to centralize care (Appendix A Fig. 1), and to improve the outcome of disease. To enable European collaborative studies and registration, a next step should be to develop European harmonized recommendations.

The recommendations in this manuscript provide guidance for physicians and other health care providers to make well-considered decisions together with patients and parents in diagnostics, treatment and follow-up of DTC in children. It is recommended that all children with DTC should only be treated in specialized expert thyroid teams with special expertise in childhood. All steps in this process should be discussed with the patient and parents to provide personalized individual medicine.

In the Netherlands, each year about eight to ten children are diagnosed with DTC. This low number in combination with the required multidisciplinary knowledge and skills is a strong incentive for centralizing the care for these patients in highly experienced hospitals

Table $\left.1{ }^{131}\right|^{-}$activity postoperative additional therapy DTC in children.

\begin{tabular}{l} 
Clinical status \\
\hline Radical resection, T1-T3a tumor, no lymph node or distant metastases \\
Irradical surgery*, T3b, N1 \\
Pre-puberty \\
Post-puberty \\
T4/M1 tumor \\
Pre-puberty \\
Post-puberty
\end{tabular}

Activity ${ }^{131} \mathbf{I}^{-}$
$1100 \mathrm{MBq}$
$100 \mathrm{MBq} / \mathrm{kg}(\max 5550 \mathrm{MBq})$
$5550 \mathrm{MBq}$
$100 \mathrm{MBq} / \mathrm{kg}$ (max $7400 \mathrm{MBq})$
$7400 \mathrm{MBq}$
Discuss in multidisciplinary local and national tumor board

The TNM classification edition 8 (2016) should be used in staging.

*Irradical surgery is defined as macroscopically or microscopically tumor in the resection margin on pathology evaluation. 
(level four) (17). In addition, to ensure high management quality, a national three-monthly, multidisciplinary tumor board has been implemented, in which all new and complex Dutch patients are anonymously discussed among the involved thyroid experts across the country. Next to this national three-monthly consultation, the level four hospitals also have a local weekly multidisciplinary tumor board (17).

Survival rates in children with DTC are favorable. Morbidity caused by treatment remains substantial, however, mainly as a consequence of surgical complications (permanent hypoparathyroidism and recurrent laryngeal nerve injury present in up to 32\%) (18). Other late effects of childhood DTC treatment include dry mouth (19) or dry eyes that may have been caused by ${ }^{131} \mathrm{I}^{-}$treatment or side effects induced by TSH suppression therapy, such as altered diastolic function (20). Awareness of these late effects of given treatment in childhood is important. By aiming to reduce these complications, steps can be made toward improving the quality of life for these children.

At this moment, evidence for the benefit of performing molecular testing in pediatric DTC, in terms of, clear clinical implications, is limited, however, it is a rapid changing area with new publications coming soon. Molecular testing may be useful to understand the tumor etiology, behavior, predict prognosis and possibly guide the development of novel treatment strategies. In pediatric DTC, up to $50 \%$ of tumors show a genetic alteration (21). BRAF mutations are less common in children compared to adults. However, in adult DTC these mutations are associated with aggressive tumors and in FNA samples the finding of BRAF is $100 \%$ specific for PTC presence $(22,23)$. For this reason, performing a total thyroidectomy when a BRAF mutation is found in a Bethesda 5 FNA sample is recommended. For the future, discussion whether a BRAF mutation in an atypical nodule (Bethesda 3 or 4 ) has treatment consequences may be indicated. In addition, it may be considered to analyze the presence of other oncogenic drivers and gene-fusions (e.g. RET/PTC and NTRK-fusions) due to the fact of increasing awareness that these are also associated with the presence of PTC. At this moment, however, the committee has stated that the current evidence to incorporate this as standard care for all children with thyroid nodules suspect for DTC is not sufficient. If possible, the committee does support the analysis of other oncogenic drivers and gene-fusions (e.g. RET/PTC and NTRK-fusions) in the FNA specimen. The results of these tests should always be discussed in the national multidisciplinary team to decide the treatment consequences in combination with other clinical determinants. The committee is very much aware of the fact that this is a rapid changing field and will update these specific recommendations each year. Possibly, in non-iodine-avid DTC, finding a genetic alteration may enable targeted therapy. Also, perhaps in the future, if targeted therapies were to give fewer side effects compared to current therapy strategies standard testing of genetic alterations could be useful.

Preoperative evaluation in pediatric DTC is needed for optimal surgical planning and additional treatment. The working group agreed with a comprehensive US of all neck regions by an experienced head and neck orientated radiologist (ATA recommendation 10), however with a footnote; the sensitivity of US investigation to detect central lymph nodes (level VI-VII) when compared to lateral nodes is lower, however the specificity may be comparable. Also, not all single suggestive findings are $100 \%$ specific (Research question C1, Appendix A) (24, $25,26,27,28)$.

The working group recommends a low dose CT thorax without contrast as the gold standard to detect pulmonary metastases. In contrast to the ATA recommendation, a chest X-ray in case of substantial cervical lymph node disease is not advised because of lack of sensitivity in this setting. In case of large or fixed thyroid masses, vocal cord paralysis, bulky metastatic lymphadenopathy or tumor invasion in the esophagus or trachea, MRI should be considered because of the higher spatial resolution and excellent soft tissue contrast, especially when minimal fat tissue in the neck is present.

The main argument for treating all DTC children with ${ }^{131} \mathrm{I}^{-}$postoperatively is that children are much more likely to initially present with lymph nodes metastases, as well as with distant metastases (29). Based on expert opinion, recommendations for ${ }^{131} \mathrm{I}^{-}$activity were proposed dependent on the individual clinical situation (Table 1). In addition, direct postoperative restaging with a ${ }^{123} \mathrm{I}^{-}$or ${ }^{124} \mathrm{I}^{-}$ WBS is not recommended due to the fact that all children will have a WBS 4 to 7 days after initial ${ }^{131} \mathrm{I}^{-}$treatment. The main arguments (for the recommendation) to wait for a minimum of 12 months for retreatment with ${ }^{131} \mathrm{I}^{-}$after initial ${ }^{131} \mathrm{I}^{-}$therapy (if necessary), is that decline of $\mathrm{Tg}$ has been reported for a prolonged time after ${ }^{131} \mathrm{I}^{-}$treatment. Also longer recovery time in between ${ }^{131} \mathrm{I}^{-}$therapy may lower the risk for late adverse effects $(30,31)$.

In contrast to the ATA recommendation to perform diagnostic WBS routinely during follow-up in intermediate and high-risk patients, the Dutch 
committee of experts found no indication to adopt this strategy because of the high sensitivity of neck US combined with Tg measurement to detect recurrent DTC (expert opinion).

Since 2015 the term 'noninvasive follicular thyroid neoplasm with papillary-like nuclear features' (NIFTP) is used. NIFTP has a prevalence of less than 5\% in the pediatric PTC population (32). Further studies are needed regarding the role of this new entity, management strategies and follow-up targets.

Our recommendation has several limitations. First of all, the method by which these recommendations were developed has a limitation. The AGREE-II instrument that was used (9) is intended to assess the quality of guidelines and is not valid to evaluate the quality of review articles.

Transition of care from pediatric to adult medicine is an important aspect in follow-up care for pediatric DTC, but has not been addressed in the current recommendation. This aspect in care should receive separate attention because it is an important aspect in the care and support of the young adult DTC patient.

Similar to the ATA pediatric guideline, these recommendations have been developed for patients $\leq 18$ years of age. However, there is a spectrum of childhood and adult DTC changing in the age group of 16-25 years (expert opinion). There are some young adults who may present with childhood DTC and who might benefit from treatment along the pediatric guideline, and vice versa. This aspect should be studied in the coming years, aiming to develop an adolescent DTC recommendation.

These new Dutch recommendations have been formulated based on the best available high-quality evidence. However, new evidence may necessitate quick adaption of the recommendations. For this reason, a dynamic flowchart was developed on Oncoguide in which the recommendations can easily be updated (www. oncoguide.nl) (33). In this way, if upcoming literature makes it necessary to update the recommendation, this can easily be done. In general it is advised to update clinical guidelines every 3 years $(34,35)$.

Recently a survey on organization and management of pediatric DTC in Europe was carried out, showing a scattering of care in Europe with limited centralization and different protocols being used (36). Collaboration between countries is needed to optimize treatment and minimize adverse long-term effects. In the absence of a European pediatric DTC guideline, these Dutch recommendations may be used as starting point for the development of a European guideline.

\section{Conclusion}

Treatment of pediatric DTC is challenging, given that children more often present with extensive and aggressive disease and have a longer life-span, making the long-term outcome of the given treatment of special importance. The optimal treatment approach of pediatric DTC is complex and cannot be captured in a one-sizefits-all model. It requires a multidisciplinary approach in thyroid cancer expertise centers. These new Dutch recommendations provide guidance. However, the importance of individual considerations evaluated by an expert national multidisciplinary meeting and shared decision making with the patient and parents should be emphasized. Besides, to optimize diagnostics, management and outcomes while minimizing the long-term adverse consequences for patients with pediatric thyroid cancer, we have to cross borders and collaborate. Development of a European guideline for management of pediatric DTC would be an essential step to achieve this. These Dutch recommendations may be used as starting point for the development of a collaborative European recommendation.

\section{Supplementary materials}

This is linked to the online version of the paper at https://doi.org/10.1530/ EJE-20-0191.

\section{Declaration of interest}

The authors declare that there is no conflict of interest that could be perceived as prejudicing the impartiality of this article.

\section{Funding}

This work did not receive any specific grant from any funding agency in the public, commercial, or not-for-profit sector.

\section{Author contribution statement}

C A Lebbink, B L Dekker, A S P van Trotsenburg, T P Links and H M van Santen contributed equally to this manuscript.

\section{Acknowledgements}

The authors would like to thank the comprehensive cancer center the Netherlands (IKNL) for developing the dynamic flowcharts on Oncoguide. The authors also would like to thank M Porrey, a patient representative, for her valuable contribution to these recommendations.

\section{References}

1 Vergamini LB, Frazier AL, Abrantes FL, Ribeiro KB \& RodriguezGalindo C. Increase in the incidence of differentiated thyroid carcinoma in children, adolescents, and young adults: a population- 
based study. Journal of Pediatrics 2014164 1481-1485. (https://doi. org/10.1016/j.jpeds.2014.01.059)

2 Siegel DA, King J, Tai E, Buchanan N, Ajani UA \& Li J. Cancer incidence rates and trends among children and adolescents in the United States, 2001-2009. Pediatrics 2014134 e945-e955. (https:// doi.org/10.1542/peds.2013-3926)

3 Spinelli C, Bertocchini A, Antonelli A \& Miccoli P. Surgical therapy of the thyroid papillary carcinoma in children: experience with 56 patients $\leq 16$ years old. Journal of Pediatric Surgery 200439 1500-1505. (https://doi.org/10.1016/j.jpedsurg.2004.06.016)

4 Busnardo B \& De Vido D. The epidemiology and etiology of differentiated thyroid carcinoma. Biomedicine and Pharmacotherapy 200054 322-326. (https://doi.org/10.1016/S0753-3322(00)80056-6)

5 Klein Hesselink MS, Nies M, Bocca G, Brouwers AH, Burgerhof JGM, van Dam EWCM, Havekes B, van den Heuvel-Eibrink MM, Corssmit EPM, Kremer LCM et al. Pediatric differentiated thyroid carcinoma in the Netherlands: a nationwide follow-up study. Journal of Clinical Endocrinology and Metabolism 2016101 2031-2039. (https://doi.org/10.1210/jc.2015-3290)

6 Francis GL, Waguespack SG, Bauer AJ, Angelos P, Benvenga S, Cerutti JM, Dinauer CA, Hamilton J, Hay ID, Luster M et al. Management guidelines for children with thyroid nodules and differentiated thyroid cancer. Thyroid 201525 716-759. (https://doi. org/10.1089/thy.2014.0460)

7 Danese D, Gardini A, Farsetti A, Sciacchitano S, Andreoli M \& Pontecorvi A. Thyroid carcinoma in children and adolescents. European Journal of Pediatrics 1997156 190-194. (https://doi. org/10.1007/s004310050580)

8 Guille JT, Opoku-Boateng A, Thibeault SL \& Chen H. Evaluation and management of the pediatric thyroid nodule. Oncologist 201520 19-27. (https://doi.org/10.1634/theoncologist.2014-0115)

9 Brouwers MC, Kho ME, Browman GP, Burgers JS, Cluzeau F, Feder G, Fervers B, Graham ID, Grimshaw J, Hanna SE et al. AGREE II: advancing guideline development, reporting and evaluation in health care. Canadian Medical Association Journal 2010182 E839-E842.

10 Dinauer CA, Breuer C \& Rivkees SA. Differentiated thyroid cancer in children: diagnosis and management. Current Opinion in Oncology 200820 59-65. (https://doi.org/10.1097/CCO.0b013e3282f30220)

11 Niedziela M, Handkiewicz-Junak D, Malecka-Tendera E, Czarniecka A, Dedecjus M, Lange D, Kucharska A, Gawlik A, Pomorski L, Wloch J et al. Diagnostics and treatment of differentiated thyroid carcinoma in children - guidelines of Polish National Societies. Endokrynologia Polska 201667 628-642. (https://doi.org/10.5603/EP.2016.0072)

12 Rivkees SA, Mazzaferri EL, Verburg FA, Reiners C, Luster M, Breuer CK, Dinauer CA \& Udelsman R. The treatment of differentiated thyroid cancer in children: emphasis on surgical approach and radioactive iodine therapy. Endocrine Reviews 201132 798-826. (https://doi.org/10.1210/er.2011-0011)

13 Spoudeas HAH \& Harrison BJ. Paediatric Endocrine Tumours, pp. 1-127. West Sussex, UK: Novo Nordisk Ltd, 2005.

14 Waguespack SG \& Francis G. Initial management and follow-up of differentiated thyroid cancer in children. Journal of the National Comprehensive Cancer Network 20108 1289-1300. (https://doi. org/10.6004/jnccn.2010.0095)

15 Clement SC, Kremer LCM, Verburg FA, Simmons JH, Goldfarb M, Peeters RP, Alexander EK, Bardi E, Brignardello E, Constine LS et al. Balancing the benefits and harms of thyroid cancer surveillance in survivors of Childhood, adolescent and young adult cancer: recommendations from the International Late Effects of Childhood Cancer Guideline Harmonization Group in collaboration with the PanCareSurFup Consortium. Cancer Treatment Reviews 201863 28-39. (https://doi.org/10.1016/j.ctrv.2017.11.005)

16 Metman MJH, Lončar I, Kruijff S, Engelsman AF \& van Ginhoven TM. Is less always more in a national well-differentiated thyroid cancer population? European Journal of Surgical Oncology 2020 46 709-711. (https://doi.org/10.1016/j.ejso.2019.10.006)

17 Díez JJ, Galofré JC, Oleaga A, Grande E, Mitjavila M, Moreno P \& Grupo de Trabajo de Cáncer de Tiroides de la Sociedad Española de Endocrinología y Nutrición. Consensus statement for accreditation of multidisciplinary thyroid cancer units. Endocrinologia y Nutricion 201663 e1-e15. (https://doi.org/10.1016/j.endonu.2015.07.005)

18 Klein Hesselink MS, Nies M, Bocca G, Brouwers AH, Burgerhof JGM, Van Dam EWCM, Havekes B, Van Den Heuvel-Eibrink MM, Corssmit EPM, Kremer LCM et al. Pediatric differentiated thyroid carcinoma in the Netherlands: a nationwide follow-up study. Journal of Clinical Endocrinology and Metabolism 2016101 2031-2039. (https://doi.org/10.1210/jc.2015-3290)

19 Selvakumar T, Nies M, Klein Hesselink MS, Brouwers AH, Van Der Horst-Schrivers ANA, Klein Hesselink EN, Tissing WJE, Vissink A, Links TP, Bocca G et al. Long-term effects of radioiodine treatment on salivary gland function in adult survivors of pediatric differentiated thyroid carcinoma. Journal of Nuclear Medicine 201860 172-177. (https://doi.org/10.2967/jnumed.118.212449)

20 Klein Hesselink MS, Bocca G, Hummel YM, Brouwers AH, Burgerhof JGM, Van Dam EWCM, Gietema JA, Havekes B, Van Den Heuvel-Eibrink MM, Corssmit EPM et al. Diastolic dysfunction is common in survivors of pediatric differentiated thyroid carcinoma. Thyroid 201727 1481-1489. (https://doi.org/10.1089/thy.2017.0383)

21 Bauer AJ. Molecular genetics of thyroid cancer in children and adolescents. Endocrinology and Metabolism Clinics of North America 201746 389-403. (https://doi.org/10.1016/j.ecl.2017.01.014)

22 Adeniran AJ, Zhu Z, Gandhi M, Steward DL, Fidler JP, Giordano TJ, Biddinger PW \& Nikiforov YE. Correlation between genetic alterations and microscopic features, clinical manifestations, and prognostic characteristics of thyroid papillary carcinomas. American Journal of Surgical Pathology 200630 216-222. (https://doi. org/10.1097/01.pas.0000176432.73455.1b)

23 Xing M, Tufano RP, Tufaro AP, Basaria S, Ewertz M, Rosenbaum E, Byrne PJ, Wang J, Sidransky D \& Ladenson PW. Detection of BRAF mutation on fine needle aspiration biopsy specimens: a new diagnostic tool for papillary thyroid cancer. Journal of Clinical Endocrinology and Metabolism 200489 2867-2872. (https://doi. org/10.1210/jc.2003-032050)

24 Leboulleux S, Girard E, Rose M, Travagli JP, Sabbah N, Caillou B, Hartl DM, Lassau N, Baudin E \& Schlumberger M. Ultrasound criteria of malignancy for cervical lymph nodes in patients followed up for differentiated thyroid cancer. Journal of Clinical Endocrinology and Metabolism 200792 3590-3594. (https://doi.org/10.1210/jc.2007-0444)

25 Fish SA, Langer JE \& Mandel SJ. Sonographic imaging of thyroid nodules and cervical lymph nodes. Endocrinology and Metabolism Clinics of North America 200837 401-417, ix. (https://doi. org/10.1016/j.ecl.2007.12.003)

26 Kuna SK, Bracic I, Tesic V, Kuna K, Herceg GH \& Dodig D. Ultrasonographic differentiation of benign from malignant neck lymphadenopathy in thyroid cancer. Journal of Ultrasound in Medicine 200625 1531-1537; quiz 1538. (https://doi.org/10.7863/ jum.2006.25.12.1531)

27 Richman DM, Benson CB, Doubilet PM, Peters HE, Huang SA, Asch E, Wassner AJ, Smith JR, Cherella CE \& Frates MC. Thyroid nodules in pediatric patients: sonographic characteristics and likelihood of cancer. Radiology 2018288 591-599. (https://doi. org/10.1148/radiol.2018171170)

28 Horvath E, Majlis S, Rossi R, Franco C, Niedmann JP, Castro A \& Dominguez M. An ultrasonogram reporting system for thyroid nodules stratifying cancer risk for clinical management. Journal of Clinical Endocrinology and Metabolism 200994 1748-1751. (https:// doi.org/10.1210/jc.2008-1724)

29 Spinelli C, Tognetti F, Rallo L, Cappelli G, Gucci M \& Strambi S. Pediatric versus adult papillary thyroid carcinoma: different 
diseases requiring different surgical approaches. Journal of Head Neck and Spine Surgery 20171 ID:555554. (https://doi.org/10.19080/ JHNSS.2017.01.555554)

30 Padovani RP, Robenshtok E, Brokhin M \& Tuttle RM. Even without additional therapy, serum thyroglobulin concentrations often decline for years after total thyroidectomy and radioactive remnant ablation in patients with differentiated thyroid cancer. Thyroid 2012 22 778-783. (https://doi.org/10.1089/thy.2011.0522)

31 Clement SC, Peeters RP, Ronckers CM, Links TP, Van Den HeuvelEibrink MM, Nieveen Van Dijkum EJM, Van Rijn RR, Van Der Pal HJH, Neggers SJ, Kremer LCM et al. Intermediate and long-term adverse effects of radioiodine therapy for differentiated thyroid carcinoma - a systematic review. Cancer Treatment Reviews 201541 925-934. (https://doi.org/10.1016/j.ctrv.2015.09.001)

32 Rossi ED, Mehrotra S, Kilic AI, Toslak IE, Lim-Dunham J, Martini M, Fadda G, Lombardi CP, Larocca LM \& Barkan GA. Noninvasive follicular thyroid neoplasm with papillary-like nuclear features in the pediatric age group. Cancer Cytopathology 2018126 27-35. (https:// doi.org/10.1002/cncy.21933)

33 IKNL. Oncoguide [Internet], 2019. (available at: https://www. oncoguide.nl/\#!/projects/64/guideline)

34 Shekelle PG, Ortiz E, Rhodes S, Morton SC, Eccles MP, Grimshaw JM $\&$ Woolf SH. Validity of the agency for healthcare research and quality clinical practice guidelines: how quickly do guidelines become outdated? JAMA 2001286 1461-1467. (https://doi. org/10.1001/jama.286.12.1461)

35 Shekelle P, Eccles MP, Grimshaw JM \& Woolf SH. When should clinical guidelines be updated? BMJ 2001323 155-157. (https://doi. org/10.1136/bmj.323.7305.155)

36 Dekker BL, Newbold KL, Führer D, Waguespack SG, HandkiewiczJunak D, Links TP \& European Initiative on Collaboration on Paediatric Thyroid Cancer. Survey on paediatric differentiated thyroid cancer care in Europe. Hormone Research in Paediatrics 2018 89 58-62. (https://doi.org/10.1159/000484170)

Received 4 March 2020

Revised version received 23 June 2020

Accepted 21 July 2020 